\title{
Back to the future? Transatlantic collaboration on ageing research
}

\author{
Richard G. A. Faragher
}

Published online: 5 January 2010

(C) American Aging Association 2009

This special issue of AGE is the result of several years of productive dialogue and joint working between the British Society for Research on Ageing (BSRA) and the American Aging Association (AAA). Beginning in 2004, the two societies undertook deliberate efforts aimed at the encouragement of first dialogue and then joint working between groups of scientists in the United Kingdom and the United States. The means chosen to encourage this was a special session reserved for British speakers at the American Aging Association. This awareness \& collaboration symposium was very well received and similar sessions have been held at the annual meetings of the American Aging Association every year since. Financial support for these has been generously forthcoming from both the International Relations Branch of the Biotechnology and Biological Sciences Research Council (BBSRC) and by Research into Ageing. Perhaps the most important role of this Editorial is to express the thanks of both learned societies to these funders. Little could have been achieved without their assistance.

The first transatlantic symposium was held in Boston in June 2005 and focussed predominantly on the work of scientists supported under the BBSRC's

R. G. A. Faragher $(\bowtie)$

School of Pharmacy \& Biomolecular Sciences,

University of Brighton,

Brighton, East Sussex BN2 4GJ, UK

e-mail: rgaf@brighton.ac.uk
Science of Ageing (SAGE) and Experimental Research on Ageing (ERA) special initiatives. These two programmes marked the first significant attempt by British state funders to support a broad programme of research into the fundamental mechanisms of the ageing process and covered the period 1997-2004. The remit of SAGE was to understand the fundamental biology of the ageing process with a particular focus on cellular senescence, the biochemistry of stress, the ageing of the immune system and the genetic determinants of life span. Focusing on normal ageing at the molecular, cellular, systems and behavioural levels; ERA followed directly from SAGE (in 2001) and supported studies into the genetics of normal ageing, new model systems for the study of the process and the development of compounds or regimes which had the potential to alter the trajectory of the ageing process (such as small molecule pharmacological agents and free radical scavengers). By adopting a mindset which aimed not simply at understanding ageing, but at intervening in it, it was hoped that ERA would lay the ground for new treatments that would improve the quality of life of older people. A total of 48 grants with a total value $£ 9.15$ million were made under these initiatives and a review of the process (in 2008) ${ }^{1}$ concluded that they

\footnotetext{
${ }^{1}$ BBSRC evaluation of SAGE and ERA http://www.bbsrc.ac. uk/organisation/policies/reviews/funded_science/0801_sage_ era.html
} 
made a major contribution to ageing research in the UK and underpin much of the research in the basic biology of ageing which have been carried out in the country since.

However, it would be wrong to assume that the United Kingdom had no presence in ageing research prior to SAGE and ERA. Since the mid-1970s the Charity Research into Ageing has supported more than 300 awards made to scientists and clinicians in the expectation that their findings would make a positive difference to the quality of later life. Research into ageing campaigned to have the potential of research to extend healthy lifespan taken seriously by UK Government and can claim a considerable amount of credit for the adoption of the Extend the Quality of Life of our Population (EQUAL) Government initiative in 1995. This initiative was designed to encourage the different British research councils to fund projects aimed at improving the quality of active life and capacity for independent living of older people and thus directly drove SAGE and ERA. ${ }^{2}$ The British Society for Research on Ageing was a major supporter of Research into Ageing at the time of its formation and has remained closely linked to it. It was thus only natural that the two organisations should work together to encourage productive joint working between scientists in different countries with a common research agenda. At the 2007 awareness and collaboration symposium, Research into Ageing showcased the work of a number of its award holders and explored the areas of disturbed circadian rhythms, stress, cellular senescence and muscle ageing. Importantly, it also provided examples of joint working between British and American scientists.

Working across disciplines as well as across countries often brings real benefit to ageing research so long as multi-disciplinarity is seen as a means to an end rather than an end in itself. A noticeable trend within British ageing research in the years from 2001 onwards was recognition by the mainstream gerontological community of the potential value of involving researchers from natural science backgrounds beyond biology (especially chemists) in the study of the

\footnotetext{
${ }^{2}$ The scope of work funded by Research into Ageing can be seen at http://research.helptheaged.org.uk/NR/rdonlyres/6F8E8FB09E77-4F3B-BC8D-8E82C537CE68/0/ageofdiscoverynot 30years.pdf
}

ageing process. This, in part, led to the establishment of the SPARC (Strategic Promotion of Ageing Research Capacity) programme in 2005. SPARC was funded by both the BBSRC and the Engineering and Physical Sciences Research Council (EPSRC) and aimed to provide pump-priming funds to newcomers to ageing research, to build national capacity in gerontology and to showcase the latest research findings. As co-Director of the programme I ensured that the SPARC community played an active role in TransAtlantic collaboration and I was particularly pleased when the 2008 awareness and collaboration symposium in Boulder played host to a group of SPARC award holders. The group had particular strengths in synthetic chemistry, small molecule effects on key ageing processes and in systems biology. The latter theme, integrative biology, was also the focus of last year's symposium held in Scottsdale.

One could be forgiven for thinking that transatlantic collaboration on the biology of ageing is a new idea. In fact, it the first intent of some of the founders of our field was to create just such a research community. In 1939, Vladimir Korenchevsky, founder of the British Society for Research on Ageing, encouraged a number of prominent American scientists closely interested in problems of ageing (including Edmund Cowdrey and Edward Stieglitz) to form the "the American branch" of the BSRA (known then as the "Club for Ageing") (Park 2008). We now know this 'American Branch' as the Gerontological Society of America. Both organisations held their first conferences in 1946 although there is archival evidence of significant collaboration between the scientists involved through the Second World War.

At the first conference of the "British Branch of the Club for Research on Ageing" Korenchevsky gave an address in which he outlined the features necessary for the growth of gerontology (Korenchevsky 1952). The text has a frightening modern ring with an emphasis above all on the need both to grow a small community and to fund it properly. Perhaps it would please our forerunners to see that our attempts to provide a permissive environment for joint working bore fruit in the decision by the BBSRC and the National Institutes on Aging (NiA) to jointly fund six projects with a total value of $£ 4$ Million. These projects are genuine joint efforts between leading researchers in British and American Universities and cover cellular senescence, new model systems, im- 
mune senescence and the role of stochastic effects on the process. Much of the operational detail required to co-ordinate this activity was discussed 'behind the scenes' at the Transatlantic symposia and support was provided by both Research into Ageing and the Alliance for Aging Research (AFAR). I hope the papers in this issue will give readers a sense of the excitement and sense of possibility which re- assured us all that good things would come from 'working across the pond'. Long may it continue.

\section{References}

Korenchevsky V (1952) Br Med J 1:375-376

Park HW (2008) J Hist Biol 41:529-572 